\title{
CONSIDERAÇÕES SOBRE A DIALÉTICA NO DIÁLOGO FILEBO
}

Sonia Maria Maciel*

SÍNTESE - A intenção do texto é apresentar aspectos da dialética platônica presentes no diâlogo Filebo. Para tal, são examinados o mito e a doutrina não escrita como recurso metodológico para mostrar o estilo platônico de fazer filosofia.

PALAVRAS CHAVE - Platão, Filebo, dialética, mito, doutrina não escrita.
ABSTRACT - The aim of this paper is to present some aspects of Plato's dialectic which are present in the dialogue Philebus. In this purpose are examineted the myth and the theory of recollection as a methodological claim to point out Plato's style of making philosophy.

KEY WORDS - Plato, Philebus, dialectic, mith, theory of recollection.

Este trabalho quer examinar aspectos da dialética platônica que são especificos do diálogo Filebo. ${ }^{1}$ Não analisa a dialética como um todo porque sendo o Filebo, junto com o Parmênides, o Sofista e o Político considerado um dos diálogos dialéticos, ele representa um momento privilegiado do método dialético de Platão.

O texto divide-se em três partes que têm como uma das funções apontar para as várias possibilidades de interpretação de um diálogo platônico. A outra é mostrar que o texto Filebo pretende atingir dois momentos bem distintos com relação à filosofia: a do mestre que sabe e quer passar seu conhecimento para seus discípulos e para isso utiliza-se de vários recursos, por exemplo o mitológico, e o outro cumpre a função de iniciar os jovens na arte de filosofar.

A palavra dialética tem sua origem etimológica estreitamente ligada a diálogo. Assim como no diálogo dois logoi se contrapõem, na dialética duas razões ou duas posições se confrontam, num acordo na discordância, por que é assim que o diálogo se estabelece. Nisso reside a importância do método dialético. Sucessivas mudanças de posições, induzidas pelas posições contrárias, vão acontecendo e isto torna o diálogo uma modalidade particular de fazer filosofia.

* Doutoranda do Curso de Pós-Graduação em Filosofia da PUCRS.

1 Platon. Ouvres Complètes. Paris; Belles Lettres, 1994.

\begin{tabular}{|l|l|l|l|l|l|}
\hline VERITAS & Porto Alegre & v. 43 & $\mathrm{n}^{\circ} 4$ & Dezembro 1998 & p. 1121-1127 \\
\hline
\end{tabular}


No diálogo Filebo a dialética platônica tem um locus privilegiado de análise pois seus argumentos são complexos e detalhados. Com isto concordam Gadamer, ${ }^{2}$ Fruchon, ${ }^{3}$ Diés ${ }^{4}$ Reale ${ }^{5}$ para citar apenas os que me detive na elaboração do texto, Filebo é relevante tanto pela importância que representa na história da ética antiga como, principalmente, pelo encadeamento que busca entre ética e ontologia, entre comportamento e fundamentação última. Portanto, mesmo que o problema ético esteja colocado no Filebo não deve ser encarado como a proposta principal. A posição ontológica ali colocada que abrange o pensamento central de Platão denominado "Doutrina da Idéias" e que perpassa todo o texto, não deve ser preterida pelo problema ético. Isto é, a posição ontológica de qual deve ser o "Bem" da vida humana e o problema ético que disso decorre estão estritamente ligados. Pois o "Bem" de que fala Platão no Filebo é um estado superior da alma, é uma elevação do espirito que se atinge pela reflexão. $\mathrm{O}$ "Bem" a ser investigado deve ser um modo de dispor-se e comportar-se da alma humana e, portanto, compreendido a priori. Isto significa que ele não é, portanto, qualquer coisa que o homem possa ter, não é qualquer coisa que seja bom, mas um modo de seu ser mesmo. A questão é então qual a disposição da alma que torna feliz a vida de todos os homens? Assim é próprio que na idéia ontológica universal do "Bem" venha justificada uma existência humana bem sucedida.

Com este intuito é realizada uma minuciosa análise dialética da hedoné e da phronesis. Portanto, é claro que Platão não pretende enunciar uma ética filosófica mas, certamente, o diálogo exprime sua intenção de, dialeticamente, como um modo particular de filosofar, tentar explicitar qual seja o ideal da existência do filósofo. Dizendo de outra forma, no dialogar, que é como Platão acredita ser possível fazer filosofia, existe uma pretensão de atingir um estágio superior de conhecimento que supere a doxa, que é o campo da opinião, para chegar a atingir o estágio do puro conhecimento, do conhecimento verdadeiro, a noesis, onde será possivel avaliar se devemos nos deixar conduzir pelos instintos, pela realidade mutável e perecivel da realidade empirica, ou devemos nos conduzir pela razão que mostra a realidade superior, imutável de natureza inteligivel.

O conhecimento e o papel critico da filosofia é o ponto de partida também neste diálogo. À filosofia, através do método dialético de distinção e diferenciação de conceitos, corresponde o papel crítico na tentativa de superação do senso comum, de sentido empirico, estabelecendo o que deve ser aceito por todos. Nesse sentido a prática filosófica visa um entrelaçamento entre o mundo sensível (ético) e o mundo das idéias (ontologia). Platão entende que é por intermédio do diálogo que isto pode acontecer. Através do método dialético pretende mostrar a fragilidade, a ausência de fundamento, o caráter de aparência das opiniões e preconceitos dos homens. O diálogo vem denunciar esses obstáculos, fazendo com que o interlocutor se dê conta disso. Não é a distinção pura e simples entre o verdadeiro e o

2 Gadamer, H.G. Studi Platonici. Trad. Giovanni Moretto. Casale, Casa Editrici Marietti, 1983.

3 Fruchon, Pierre. L'herméneutique de Gadamer. Platonisme e modernité. Paris, Les éditions du Cerf, 1994.

4 Diés, Auguste. In: Platon - Ouvres Complètes. Trad. Auguste Diés. "Notice”, Paris, 1949.

5 Reale, Giovanni. Para uma nova interpretação de Platão. São Paulo, Edições Loyola, 1997. 
falso, mas uma busca de definições e de clareza sobre o sentido das coisas, para chegar a estabelecer o significado do que se diz. Assim a dialética é também, no início, um processo de abstração que possibilitará a definição de conceitos, onde poderão se dar, provisoriamente, algumas contradições que têm o intuito de mostrar ao interlocutor a fragilidade de suas crenças para que possam ser superadas. Contudo, não é simplesmente a substituição de uma opinião por uma certeza. 0 método dialético que se desenvolve no Filebo, especificamente, é um método crítico que pretende mostrar a necessidade da interrogação e um questionamento da própria opinião sobre o que seja hedoné e episteme, sua origem e seus fundamentos sua essência, ou seja, a natureza do prazer e do conhecimento. É no diálogo que a relação entre o que se diz e seu significado procura uma interpretação.

\section{II}

O tema que movimenta o diálogo Filebo desde o início é o "Bem" da vida humana, isto é, como o homem poderia alcançar a felicidade. Como isto se confronta com duas possibilidades diversas, ou seja, uma defendida por Filebo que acredita ser o prazer, a alegria o supremo "Bem" para o homem e outra, sustentada por Sócrates de que o supremo "Bem" para o homem encontra-se numa particular possibilidade de seu ser, já que o homem pode pensar, compreender, recordar e com isso pode dispor do mundo que o cerca através da reflexão, se impõe uma explicitação mais profunda e detalhada desses dois enunciados.

O fenômeno que se evidencia é, não só aquele que está formulado proposicionalmente, mas também o que se mostra no quadro das figuras que estão fazendo parte do diálogo, do papel que ocupam Sócrates e Filebo, cada um respectivamente representando o conhecimento, a razão e o gozo, o prazer. Portanto, diante dessa perspectiva, a pesquisa sobre o "Bem" propriamente humano não pode ser feito somente no exercício dialético e na conseqüente formulação de seu princípio. Para além da explicitação dos princípios que regem o "Bem" na vida do homem, existe algo que escapa à formulação e à sua elucidação conceitual.

Filebo não está colocado no diálogo como uma pobre figura que se retira para dar lugar a um outro que faria às vezes de interlocutor de Sócrates sem uma razão muito particular. Algum significado Platão pretendeu com isso. Certamente, representado dessa forma, recusando-se deliberadamente a entrar no diálogo, Filebo mostra a potência e a coerência com o princípio do prazer. $O$ seu retirar-se do diálogo pretende denunciar que no prazer não existe necessidade alguma de justificação. A universalidade que o rege é aquela que impulsiona todo o ser vivente na busca do prazer. Mesmo para o homem que se distingue por possuir memória e reflexão, como suas características mais significativas, o principio do prazer é decisivo e exclui qualquer argumentação, isto porque, o princípio do prazer é anterior e exterior e impõem-se por si mesmo.

Como se vê a tese de Filebo é, à sua maneira, insuperável ela escapa aos desafios da dialética pela simples razão que o ser humano não escolhe a busca do prazer, ele não faz mais do que seguir à potência secreta da pulsão vital.

Diante dessas evidências Sócrates, pelo menos provisoriamente, tem em Filebo uma figura de respeito. Platão com isto quer demonstrar o poder a força e do 
dogmatismo do prazer do qual Filebo é o representante. Contra essa força Sócrates se vê obrigado a afirmar que ele não é mais do que um membro da família do Olimpo, com isso querendo anunciar não somente os caminhos por onde andará a dialética, em face a universal evidência do prazer, mas referindo-se à deusa Afrodite, como sendo a protetora de Filebo, reforça ainda mais a natureza do prazer já que os deuses conduzem-se por sua natureza, deixam-se levar por ela. ${ }^{6} \mathrm{O}$ princípio da distinção que faz o jogo da dialética e que aqui pretende encontrar um princípio universal capaz de reger a felicidade humana, mostra-se de início completamente desprovido de autoridade diante da evidência global do princípio do prazer. O afastamento de Filebo mostra, sobretudo, a limitação que o princípio do prazer impõe à racionalidade no desenvolvimento do diálogo. Nesse sentido a análise dialética torna-se particularmente significativa.

Este é um ponto de partida importante que também deve ser assegurado ao diálogo. Protarco, então, assume a tese de Filebo, se deixa conduzir, com alguma resistência, no movimento racional fazendo com que o jogo de opostos da dialética possa acontecer. No entanto, no menos aparente do diálogo, existe um certo enigma que não pode deixar de ser considerado. Protarco que ofereceu uma certa resistência em aderir ao diálogo quando Sócrates recorre ao princípio da distinção, segue-o sem dificuldade alguma, o segue quando este recorre a um certo mistério.

É compreensível que Protarco não acompanhe Sócrates imediatamente, no desenvolvimento da dialética do "um e do múltiplo". Isto é a substituição da evidência global do prazer pela distinção dos prazeres onde a questão de sua unidade é enfocada a partir do seu ser bom. Fica difícil de compreender, no entanto, como Protarco depois de ter analisado os aspectos destinados a mostrar a superioridade da inteligência frente ao prazer, a partir da "doutrina dos quatro gêneros" que conduziu à assimilação global do "prazer ao infinito" e da "inteligência ao gênero da causa" e ainda a uma outra ruptura que acontece no movimento do diálogo que aparentemente parecia tocar em seu fim mesmo, a questão colocada por Sócrates de saber "onde e como [...] prazer e conhecimento se manifestam no visível" (15b), todas questões que conduzem ao desenvolvimento teórico sobre os princípios da dialética, se deixe convencer, sem qualquer resistência, pela seqüência socrática do diálogo. Isto é, Protarco é colocado em cheio no movimento da dialética, quando Sócrates recorre a um modo simbólico de expressão, o do misterioso oráculo, "conhecimento obscuro ou [...] sonho vago" (20b) o qual renuncia a toda autoridade e acede a um estágio dialógico de igualdade com seu interlocutor.

A forma de apresentação do diálogo leva à interpretação de um ensinamento importante, isto é, que o diálogo pode, sem dúvida, conduzir seu interlocutor sobre o terreno do simbólico e da metáfora, que o diálogo não exclui esse terreno e que o texto não visa só o campo do conceitual.

6 O recurso ao mito, utilizado por Platão, é recorrente no texto e cumpre uma função, no sentido que o discurso mitológico impõem-se por si mesmo, diferenciando-se do discurso racional. A diferença acontece na medida em que no mito o processo de aquisição desse conhecimento é diferente. $\mathrm{O}$ discurso mítico fala de um tempo longinquo, de um tempo das origens, tempo dos deuses e dos heróis do qual só as musas podem nos fazer lembrar, pois sem elas não podemos saber daquilo que não vimos. Mythos como oposto de logos quer dizer: reunir, ou associar fragmentos e indícios de fatos verificáveis. Mythos é contar uma história sobre a qual não se tem responsabilidade: ouk emos ho mythos: não inventei isso apenas ouvi falar por aí. 
No Filebo a dialética socrática aparece de modo marcante no seu exercício, no seu acontecer, isto é, na aplicação da arte da distinção à "multiplicidade concreta da experiência" (16d), em lugar de distinguir seus princípios, direta e dogmaticamente, em um sistema. Isto faz com que os intérpretes estejam voltados também para este campo que o diálogo não exclui. Recorrendo ao simbolismo do oráculo, por exemplo, Sócrates pretende destituir-se de toda autoridade e fazer com seu interlocutor um jogo dialético, isto porque a dialética, como arte da justa distinção não é uma arte secreta reservada aos filósofos, mas ao contrário faz parte da vida de todo ser humano e de seu ser mesmo.

\section{III}

$\mathrm{Na}$ leitura de um texto platônico estão implícitas várias questões e entre elas surge como relevante a que se refere à historicidade, isto é, quando se lê um diálogo toda a história da filosofia ocidental está em jogo. Aquele que lê um diálogo o faz desde a perspectiva da filosofia contemporânea com todos os pré-conceitos que aí estão envolvidos. Isto faz com que a interpretação se estabeleça a partir de uma relação triangular, ou seja, a relação do intérprete com seus contemporâneos e destes com seus predecessores. Tal é o contexto em que se encontra situada a pretensão de todo aquele que se lança nesta caminhada - marcada pelos mais diversos modos de expressão e compreensão dos diálogos platônicos.

Nesse sentido ter como meta o estudo de um diálogo platônico não pode ser outro que o de ver nele a transmissão de reflexões filosóficas e, em particular, como "forma de transmissão" sempre inacabada e aberta da filosofia de Platão. Mobilidade com um caráter sempre provisório da expressão é também o ponto que marca o texto Filebo que não exclui o sistema, ou ao menos, a visão do "Uno" e do "Bem" que não pode conhecer qualquer realização definitiva.

Dentro desta perspectiva se apresenta uma questão importante na transmissão dos diálogos, trata-se da "tradição indireta" na qual o Filebo é peça de destaque. Não são poucos os estudos modernos, sobretudo os de Giovanni Reale, ${ }^{7}$ que assinalam a suprema importância da "doutrina esotérica". Ela está reservada aos iniciados e, portanto, não poderia ser escrita, pois, se alguém a lesse e não fosse aluno da Academia, não estaria capacitado para entendê-la. Portanto, estaria reservada somente ao circulo restrito de seus membros. Pode-se concluir disso que na Academia o diálogo entre seus freqüentadores era algo de muito precioso, pois ali era discutido o que havia de mais importante.

Durante muito tempo o diálogo Filebo foi considerado como inautêntico porque ali eram levantadas questões que não estavam em nenhum outro lugar, pelo menos não da mesma forma. Com os estudos filológicos e a recuperação de vários elementos que proporcionaram um conhecimento histórico mais acabado, referente à doutrina das Idéias e sua relação com o "Bem", o diálogo Filebo foi incluido entre os autênticos.

7 Reale, G. Op. cit., p. 187. 
Mas é nesse ponto, que, segundo Fruchon, ${ }^{8}$ se coloca uma questão importante relacionada à "tradição direta" e "tradição indireta". De onde deveremos partir? É claro que não estamos dispostos a desqualificar nenhuma fonte e por conseguinte deveremos estar atentos ao que se mostra dentro desse quadro.

Os diálogos platônicos foram escritos na Grécia a mais de 2400 anos e no entanto, eles têm um privilégio metódico a partir do qual não podemos afirmar que eles sejam o resultado de uma tradição. Eles são autênticos e não o resultado de uma reconstrução. Mas a isso pode-se colocar como resposta que a obra de Platão apesar de ter sido escrita na Grécia hà muitos anos, apesar disso e acima disso, a obra é diálogo. Isto, segundo Gadamer, ${ }^{9}$ é que dá amplitude a interpretação pois assim tradição direta e indireta adquirem um certo parentesco.

Pode-se compreender assim que Platão compôs seus diálogos escritos para atingir um círculo mais amplo que aquele da Academia ao qual estavam reservados seus ensinamentos orais. O diálogo escrito, portanto, submetido a outras leis que aquela do diálogo oral e expressão de uma arte de escrever da qual Platão foi mestre, se nos apresenta como uma obra literária capaz de regrar sua própria interpretação. Isto, de certa forma, se apresenta como privilégio da "tradição direta" sobre a "tradição indireta".

Mas há uma outra situação que o diálogo apresenta e que decorre diretamente da natureza da atividade e da comunicação filosófica: os diálogos nos colocam em presença não de doutrinas constituídas, separadas do movimento de pensar que lhes deu origem, mas nos colocam em cheio nesse próprio movimento porque cada um deles é uma "totalidade de discurso independente". Longe de se reduzir a um material a partir do qual não poderíamos mais do que reconstruir as doutrinas de seu autor o diálogo platônico é, para Fruchon, ${ }^{10} \mathrm{O}$ interlocutor que nos faz participar de seu trabalho e que regra assim o nosso trabalho de interpretação. Nesse particular é que "tradição direta "e "tradição indireta" se distanciam dos propósitos verdadeiramente platônicos no que se refere ao movimento filosófico mesmo. "Tradição indireta", a transmissão escrita, passando pelo crivo dos intérpretes daquilo que foi diálogo, é agora um esqueleto abandonado e desqualificado de seus propósitos de guiar nossa liberdade de construção, seja porque nos retirou o que havia de verdadeiramente platônico nos mesmos, sua forma dialógica de fazer filosofia, seja porque os questionamentos que ali existem, quando existem, não são mais os de Platão mas os de Aristóteles, de Plotino, de Proclo, entre outros. A "tradição indireta" obviamente é importante e tem seu papel assegurado na historia da filosofia, mas como reconstrução filológica dos interlocutores de Platão e não como o próprio filosofar que os diálogos suscitam. Assim, o que funda o privilégio do gênero literário diálogo na filosofia é o mesmo que lhe deu origem: "A filosofia mesmo, não tendo que ser mais que atividade, não se deixa fixar por nenhuma doutrina." 11

8 Fruchon, Pierre. Op. cit., p. 335.

9 In Fruchon, Pierre. Op. cit., p. 341.

10 Idem, p. 342.

11 Fruchon, Op. cit., p. 363. “Que la philosophie même, n'ayant d'être que comme activité, ne se laisse fixer em aucune doctrine." 
Assim é que os três momentos deste texto se encontram. O diálogo Filebo, como todos os diálogos platônicos, serve ao propósito de fazer filosofia, pois seus conteúdos nos suscitam sempre novos questionamentos. Ele tem o poder de nos assinalar os problemas que o tema suscita, porque ele dá algo a compreender, mas nos convida a novos caminhos, a prolongar seu curso, a repetir em ato os questionamentos do diálogo. A dialética, certamente percorre esses caminhos. 